\title{
Why does society accept a higher risk for alcohol than for other voluntary or involuntary risks?
}

\author{
Jürgen Rehm ${ }^{1,2,3,4,5^{*}}$, Dirk W Lachenmeier ${ }^{5,6}$ and Robin Room ${ }^{7,8,9}$
}

\begin{abstract}
Background: Societies tend to accept much higher risks for voluntary behaviours, those based on individual decisions (for example, to smoke, to consume alcohol, or to ski), than for involuntary exposure such as exposure to risks in soil, drinking water or air. In high-income societies, an acceptable risk to those voluntarily engaging in a risky behaviour seems to be about one death in 1,000 on a lifetime basis. However, drinking more than $20 \mathrm{~g}$ pure alcohol per day over an adult lifetime exceeds a threshold of one in 100 deaths, based on a calculation from World Health Organization data of the odds in six European countries of dying from alcohol-attributable causes at different levels of drinking.

Discussion: The voluntary mortality risk of alcohol consumption exceeds the risks of other lifestyle risk factors. In addition, evidence shows that the involuntary risks resulting from customary alcohol consumption far exceed the acceptable threshold for other involuntary risks (such as those established by the World Health Organization or national environmental agencies), and would be judged as not acceptable. Alcohol's exceptional status reflects vagaries of history, which have so far resulted in alcohol being exempted from key food legislation (no labelling of ingredients and nutritional information) and from international conventions governing all other psychoactive substances (both legal and illegal). This is along with special treatment of alcohol in the public health field, in part reflecting overestimation of its beneficial effect on ischaemic disease when consumed in moderation.
\end{abstract}

Summary: A much higher mortality risk from alcohol than from other risk factors is currently accepted by high income countries.

Keywords: Acceptable risk, Alcohol, Mortality, Patterns of drinking, Risk, Voluntary versus involuntary risk

\section{Background}

Dealing with risk is a critical, complex and not always fully consistent endeavour in modern high-income societies [1,2]. This contribution will examine the way the risks associated with alcohol are handled, restricting our examinations to mortality and health risks. We first introduce the classic separation between involuntary and voluntary risks [3]. Voluntary risk is associated with activities in which individuals participate by choice, and where they use their own value system and experience to determine if the risk of a voluntary activity is acceptable to them. Examples are to smoke, to consume

\footnotetext{
* Correspondence: jtrehm@gmail.com

'Centre for Addiction and Mental Health, 33 Russell Street, Toronto, ON M5S 2S1, Canada

${ }^{2}$ Addiction Policy, Dalla Lana School of Public Health, University of Toronto, Toronto, Canada

Full list of author information is available at the end of the article
}

alcohol or to ski. Involuntary risks are associated with activities, conditions or events to which individuals might be exposed without their consent. Examples of involuntary risks include the risks of natural disasters (earthquakes, floods, and so on), or technology-related risks such as bad air quality or contaminated water. As Starr showed in his seminal paper [3], societies tend to accept much higher risks for voluntary behaviours than for involuntary exposure. The latter risks are often dealt with by special agencies such as the Environmental Protection Agency in the US or the European Environment Agency in Europe.

Voluntary risks are dealt with by a variety of means. These include total or partial prohibitions on commerce in risky behaviours, such as no tobacco sold to minors, as stipulated by the Tobacco Framework Convention [4]; heroin production and sale prohibited except for medical and scientific purposes [5] (both of which also remind 
us that some of the answers to minimizing risk go beyond national governments); or a minimal legal purchasing age for alcohol [6]. Or governments may gently discourage the behaviour with controls on availability or on price, for instance with Pigouvian taxes [7] (taxes applied to a market activity or product that is generating cost for individuals or society - so-called negative externalities), including taxes to channel consumption and behaviour for public health purposes [6]. But in many cases these risks are left to individual choice, and only education or guidelines are provided. However, exceptions will be made if lives of others are concerned. Thus, where behaviour such as drinking alcohol or smoking cigarettes results in involuntary risks to others, limits are often imposed, for example, interdiction of smoking in restaurants and public places in reaction to risks from involuntary smoking; per se laws to disallow operating machinery or driving after drinking. Certain risks are between voluntary and involuntary, such as the risk of participating in motor traffic (while some participation is voluntary, other participation is necessary for earning money; and some of the risk is from others' behaviour), or risks associated with various food groups (for example, exposure to salmonella will be involuntary, but exposure to saturated fats listed on the label is considered voluntary). Such risks are usually regulated by specialized agencies, stipulating rules to limit risks by thresholds for ingredients in food (for example, the Joint Food and Agriculture Organization/World Health Organization (WHO) Expert Committee on Food Additives at the international level [8], the Food and Drug Administration (FDA) in the US, and the European Food Safety Authority in Europe), or by specific rules such as speed limits, safety belts or safety requirements for baby walkers or bunk beds - for instance, by the US Consumer Product Safety Commission.

Alcohol consumption is a major risk factor for mortality and burden of disease globally in most middle and highincome countries [6,9]. Figure 1 shows the average odds of dying from different levels of alcohol exposure up to age 70 for six countries of the European Union (EU). The countries were selected to include at least one from each of the three prototypical drinking pattern traditions in Europe [10-12]. Italy was selected to represent the wine-drinking countries in the Mediterranean region, where wine is often consumed daily, usually with meals and avoiding drunkenness. Italy is also the second lowest consuming country in the EU [6], and has one of the lowest rates of alcoholuse disorders [13]. Ireland was selected as typical for the Central-West and Western regions, with beer as the beverage of choice, and with higher consumption and proportionally less drinking with meals than in Italy. The level of consumption is close to the European average $[6,14]$. Four different countries were selected for Nordic and Central-East and Eastern regions, which share a traditional style of irregular heavy drinking, mostly outside

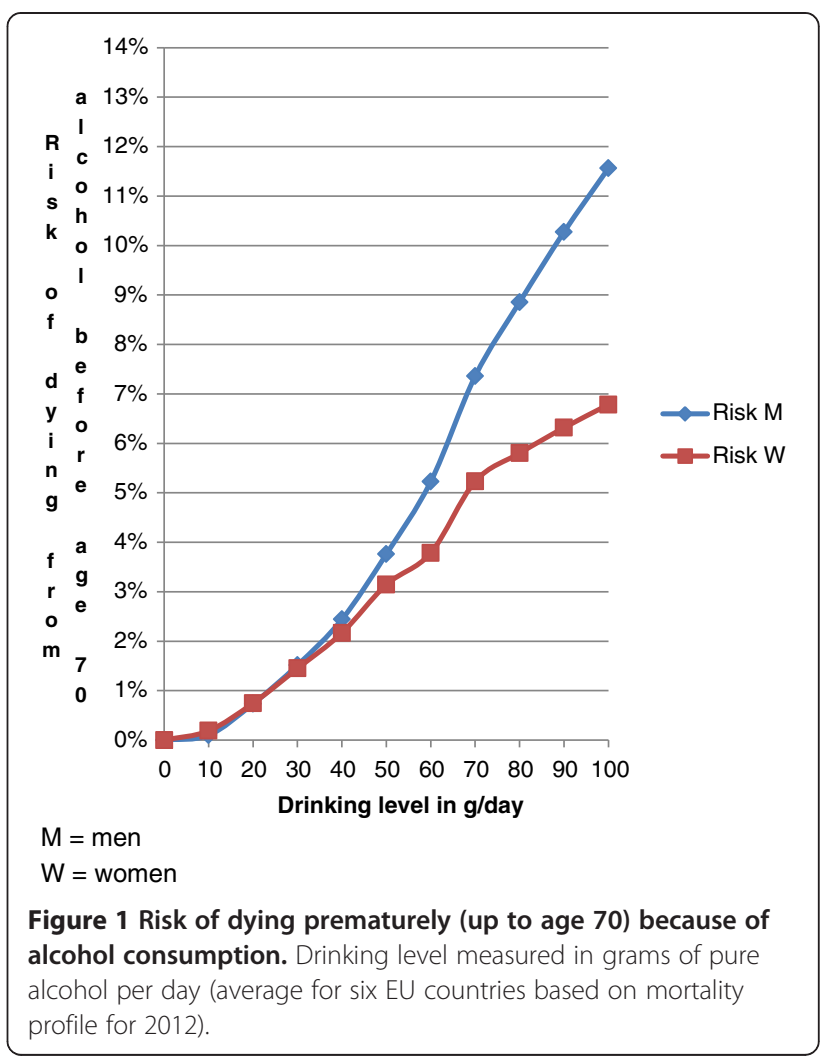

meals. The countries selected represent some variation in wealth and life expectancy $[15,16]$ : for the Nordic countries, Finland was selected; Estonia was chosen as representative of the Central East/Eastern European EU countries with the lowest gross domestic product at purchasing power parity per capita and lowest life expectancy, with one of the highest rates of alcohol-use disorders in the EU [13]; Hungary as a medium wealthy country for this region with high alcohol consumption; and Poland as a relatively rich country with one of the longest life expectancies in this region.

The odds of dying from different levels of alcohol are stated in absolute-risk terms but are based on the levelspecific relative risks applied to the mortality patterns of these countries in 2012, where the effects of current drinking had been subtracted and where competing risks had been removed (see Additional file 1 for details; for an overview of relative risks of alcohol by level of drinking, see $[17,18]$; for current burden of alcohol by country, see [6]; for competing risks, see [19]). The lifetime risk of dying was estimated assuming steady average daily alcohol consumption from age 15 and up. The difference in odds by gender is the net effect of the overall higher mortality risks of men compared to women at any age and for almost any causes, but particularly for injuries, moderated by the higher relative mortality 
risks for women than for men from biological actions of alcohol at any given level of drinking $[17,18]$.

How do these risks compare to other acceptable risks in society? Many of the fully involuntary risks, such as unsafe water provided to a household, have risk thresholds set at one in one million $\left(1\right.$ in $\left.10^{6}\right)$. Indeed, the one in one million has become something of a gold standard of acceptable risk for involuntary exposure and has been used in different areas such as water safety in Australia and the US $[20,21]$, or for increases of exposure to carcinogens in air, sediment or soil [22]. It should be noted that other standards have been used, and sometimes we see ranges, such as one in a million to one in 100,000 (see also [23]). Starr [3] found that the public seems to be willing to accept voluntary risks roughly 1,000 times greater than involuntary risks. By this standard, an acceptable risk for voluntary risks experienced by the drinkers themselves is one in 1,000 deaths for the pattern of behaviour over a lifetime.

\section{Discussion}

If we accept the stated acceptable risk of one in 1,000 deaths, drinking $20 \mathrm{~g}$ pure alcohol per day (equivalent to 1.5 to 2.5 standard drinks dependent on the national standard drink: $8 \mathrm{~g}$ pure alcohol per drink in the UK, between 10 and $14 \mathrm{~g}$ in other European countries) exceeds this threshold, even if only the risk up to age 70 is considered (obviously, the lifetime risks for alcohol-attributable mortality will be considerably higher). Although cause-ofdeath statistics become problematic for older ages [24], and thus the estimated risks are more uncertain, drinking $20 \mathrm{~g}$ pure alcohol per day seems to exceed a threshold of one in 100 for death on a lifetime basis. To put this in perspective, the average level of daily consumption in EU countries in 2012 was about 31 g pure alcohol per day among drinkers, entailing a mortality risk beyond this threshold. This level of drinking has led to a situation where every seventh death in men and every $13^{\text {th }}$ death in women before age 65 in the EU is caused by alcohol [25].

Clearly, this level of risk is not acceptable by usual standards. This finding of an unacceptable risk from the daily drinking of $20 \mathrm{~g}$ can be confirmed by the traditional risk assessment methodology in chemical toxicology, which determines an acceptable daily intake (ADI) based on a threshold on the dose-response curve combined with a safety factor (see WHO International Programme on Chemical Safety for methodology [26]). The ADI for alcohol was determined to be $2.6 \mathrm{~g} /$ day based on doseresponse modelling of epidemiological data for liver cirrhosis morbidity and mortality [27], which can be interpreted as a "virtually safe dose". Exceeding this dose, which would be caused by drinking even one standard drink per day, would normally be interpreted as a concern in terms of health, making the food unacceptable for consumption (for example, in cases of additives or pesticides exceeding ADI). Clearly, the ADI also needs to be interpreted in light of the difference between voluntary and involuntary risks. Otherwise, any alcoholic beverage would not be marketable per se.

It is harder to estimate the involuntary mortality risk from alcohol exposure, and only a few studies have tried [28,29]. In Australia, there was a yearly burden in 2008 of 367 deaths and almost 14,000 hospitalizations due to drinking by others [30], indicating yearly risks of higher than one in 100,000 deaths, and about 0.5 per 1,000 hospitalizations, the former clearly much higher than the usually accepted involuntary risk of one in one million [3,22]. Thus, it seems that alcohol-attributable voluntary and involuntary mortality risks exceed usual thresholds.

What are the factors leading to this situation? First, alcohol is not internationally regulated as an addictive substance along with illegal drugs, tobacco and pharmaceuticals [31], despite ranking as more harmful to the individual and to society than most of the substances being regulated this way, no matter what criteria are applied [32]. The lack of international regulation started as a historical accident, reflecting a long era of reaction against the alcohol prohibitions imposed in the early 20th century in more than a dozen countries [33]. That alcohol is not internationally regulated also reflects its cultural acceptance among elites in most western societies, and the strong political influence of global alcohol producers [34]. The most recent WHO Expert Committee on Drug Dependence discussed whether alcohol should be considered for coverage by the international drug treaties, and recommended that a pre-review of this should be considered [35]. But it is a long way from this to any effective public health regulation internationally, if only to protect national alcohol policies from further erosion under the international trade agreements.

Second, alcohol is not treated like other food products. While food products need to declare all their ingredients in the EU and North America, alcohol does not. In the US, alcohol was not considered a food in the temperance era, and alcoholic beverages are still regulated by a different government agency (Alcohol and Tobacco Tax and Trade Bureau) from foods (FDA). In Europe, alcoholic beverages are regulated under general food laws (Regulation (EC) No. 178/2002). However, alcoholic beverages have been exempted from the mandatory labelling of the list of ingredients and the nutrition declaration according to Regulation (EU) No 1169/2011 on the provision of food information. Whether alcoholic beverages should in future be covered by the regulation is currently under discussion. Moreover, alcohol is a well-known carcinogen with a causal role in oral cavity, pharynx, larynx, oesophagus, colon, rectum, liver (hepatocellular carcinoma) and female breast cancer [36], and its concentrations in usual daily use 
in Europe substantially exceed thresholds typically accepted for carcinogens in foods [37]. Interestingly, under California's Health and Safety Code, a warning sign must be posted in stores selling alcohol, stating that alcohol increases cancer risk [38]. This regulation was established by the Office of Environmental Health Hazard Assessment.

Third, alcohol is often treated ambivalently by the public health community, partly as a generational reaction against temperance movements, which had had strong public health support [39], and also because of the often-overestimated beneficial effect of light to moderate drinking on ischaemic diseases and diabetes (see [18] for an overview). However, these protective effects have already been considered by all of the calculations on alcohol-attributable burden, and the burden reported in the introduction here [6,9] is net burden.

Fourth, the risks of alcohol may not be fully understood by the general public. Surveys in many high-income countries showed that the impact of alcohol on cancer was known only by a minority: $33 \%$ in a large general population survey in Canada 2008, [40]; 30\% on average in CAMH Monitor - representative surveys for the province of Ontario - in 1996, 2004, 2007, 2012 (personal communication from Ms. A. Ialomiteanu); 38\% in the US [41]; $14 \%$ in the UK [42]; and only $36 \%$ of the EU population "agree totally" that alcohol can increase the risk of cancer [43]. Thus, the acceptable risk threshold by individuals and in societies may be in part based on incomplete information (see $[44,45]$ for risk perception in general; see [46] for a systematic review, how being conscientious of the risks may impact individual decisions and mortality). However, there may be other individual-level variables that impact on risk perception for alcohol, such as personal risks from alcohol being seen as much lower than risks of the same amount of consumption in others [47].

In assessing mortality risk and health burden due to alcohol consumption, one should not overlook that the burden of alcohol goes well beyond the health field and includes social consequences to those around the drinker and to wider society, such as crime, lost productivity, family problems, child neglect or abuse, and social marginalization [48]. An Australian study found that the reported tangible costs from out-of-pocket expenses and time lost because of others' drinking were of much the same magnitude as the costs to health, social and legal systems of dealing with problems from drinking [30]. While it may prove hard to integrate the metrics of the burden of these social consequences with the health burden, they underline the necessity to change our negligent attitude towards alcohol consumption and its risk. After all, there are policy measures to reduce the risk and burden associated with alcohol [49], which have even been shown to be costeffective [50].
Even after all of the discussion above, questions remain about why societies appear to accept a higher risk for alcohol than for other voluntary risks. If better information is crucial (see above), the lack of knowledge could be overcome with awareness campaigns and proper content labelling of alcohol, including warnings of health risks, as currently discussed in the EU and in Canada. However, empirical studies showed only limited outcomes, at least in the short run and with respect to drinking behaviour [51]. Can it be that the addictive properties of alcohol cloud the consumers' ability to assess information and make a free choice [52]? Or may the actual or perceived pleasurable effects of alcohol consumption (that is, benefits) be so high that the informed choice of a mortality risk in the 1:100 range is seen as "reasonable risk" [53], so that there is no pressure from the public for government action, and governments are dissuaded from effective alcohol policies such as raising taxes [54]?

\section{Summary}

Alcohol consumption incurs voluntary and involuntary risks that exceed the risks modern societies in high-income countries are willing to accept for other risk behaviours and factors. This acceptance is exemplified by how alcohol is treated within the food legislation, within the international treaties for psychoactive substances and within public health frameworks. While lack of information about alcohol-attributable risks may play a role, the reasons why alcohol is treated so exceptionally are currently not fully understood.

\section{Additional file}

Additional file 1: Risk of dying due to alcohol for different levels of average drinking in six European countries. Methodology for the calculations.

\section{Competing interests}

The authors declare that they have no competing interests.

\section{Authors' contributions}

JR conceptualized the article, collected the data from WHO and conceptualized the data analyses. DWL contributed information about food regulations and involuntary acceptable risks. RR contributed specific information on the history and current practice of alcohol control policies and international treaties. All authors have been involved in the drafting of the article and the interpretation of the data and in critical revisions of the content. All authors have given final approval of the version to be published; and agree to be accountable for all aspects of the work in ensuring that questions related to the accuracy or integrity of any part of the work are appropriately investigated and resolved. All authors read and approved the final manuscript.

\section{Authors' information}

$J R$ is a trained psychologist and methodologist, but has been working for the past 20 years in the areas of comparative risk assessment and epidemiology, currently as director of the Social and Epidemiological Research Department of the Centre for Addiction and Mental Health, Toronto, Canada. DLW is chief toxicologist, state-certified food chemist and head of the official alcohol control laboratory, Chemical and Veterinary 
Investigation Agency, Karlsruhe, Germany, and a scientist at the Institute of Clinical Psychology and Psychotherapy, Technical University of Dresden, Germany. He has a PhD in Forensic Toxicology and conducts research on food and alcohol-related risks. RR is a sociologist, who has specialized in analysing the formal and informal impact of society on substance use. He is currently working as Director of the Centre for Alcohol Policy Research, Turning Point, Melbourne, Australia, and as Professor of Social Research in Alcohol, School of Population Health, at the University of Melbourne.

\section{Acknowledgment}

The research leading to these results or outcomes has received funding from the European Union's Seventh Framework Programme (FP7/2007-2013), under Grant Agreement number 266813 - Addictions and Lifestyle in Contemporary Europe - Reframing Addictions Project (ALICE RAP - http://www.alicerap.eu). Participant organizations in ALICE RAP can be seen at http://www.alicerap.eu/ about-alice-rap/partner-institutions.html. The views expressed here reflect those of the authors only and the European Union is not liable for any use that may be made of the information contained therein. We thank Gerrit Gmel and Kevin Shield for conducting some of the analyses leading to the estimation of odds of dying, and Ulrich Frick, Gerrit Gmel and the reviewers of BMC Medicine (lan Gilmore, Wenbin Liang, Tim Stockwell) for helpful comments on earlier versions of this text. We thank Michelle Tortolo for referencing.

\section{Author details}

${ }^{1}$ Centre for Addiction and Mental Health, 33 Russell Street, Toronto, ON M5S 251, Canada. ${ }^{2}$ Addiction Policy, Dalla Lana School of Public Health, University of Toronto, Toronto, Canada. ${ }^{3}$ Department of Psychiatry, Faculty of Medicine, University of Toronto, Toronto, Canada. ${ }^{4}$ Institute of Medical Science, University of Toronto, Toronto, Canada. ${ }^{5}$ Clinical Psychology and Psychotherapy, Technische Universität Dresden, Dresden, Germany. ${ }^{6}$ Chemisches und Veterinäruntersuchungsamt Karlsruhe, Karlsruhe, Germany ${ }^{7}$ Centre for Alcohol Policy Research, Turning Point, Fitzroy, VIC, Australia. ${ }^{8}$ Melbourne School of Population \& Global Health, University of Melbourne, Melbourne, Australia. ${ }^{9}$ Centre for Social Research on Alcohol \& Drugs, Stockholm University, Stockholm, Sweden.

\section{Received: 19 August 2014 Accepted: 18 September 2014}

Published online: 21 October 2014

\section{References}

1. Beck U: Risikogesellschaft. Auf dem Weg in eine andere Moderne. Suhrkamp: Frankfurt, Germany; 1986.

2. Lupton D: Risk. New York: Routledge; 1999.

3. Starr C: Social benefit versus technological risk. Science 1969, 165:1232-1238.

4. WHO Framework Convention on Tobacco Control. http://www.who.int/fctc/en/.

5. United Nations Office on Drugs and Crime: The International Drug Control Conventions. New York: United Nations; 2013.

6. World Health Organization: Global Status Report on Alcohol and Health. Geneva, Switzerland: World Health Organization; 2014.

7. Pigou AC: The Economics of Welfare. London, UK: Macmillan; 1920

8. Joint FAO/WHO Expert Committee on Food Additives (JECFA). http://www.who.int/foodsafety/areas_work/chemical-risks/jecfa/en/.

9. Lim SS, Vos T, Flaxman AD, Danaei G, Shibuya K, Adair-Rohani H, Amann M, Anderson HR, Andrews KG, Aryee M, Atkinson C, Bacchus LJ, Bahalim AN, Balakrishnan K, Balmes J, Barker-Collo S, Baxter A, Bell ML, Blore JD, Blyth F, Bonner C, Borges G, Bourne R, Boussinesq M, Brauer M, Brooks P, Bruce NG, Brunekreef B, Bryan-Hancock C, Bucello C, et al: A comparative risk assessment of burden of disease and injury attributable to 67 risk factors and risk factor clusters in 21 regions, 1990-2010: a systematic analysis for the Global Burden of Disease Study 2010. Lancet 2012, 380:2224-2260.

10. Iontchev A: Central and Eastern Europe. In Alcohol and Emerging Markets: Patterns, Problems, and Responses. Edited by Grant M. Washington, DC: International Center for Alcohol Policies; 1998:177-201.

11. Popova S, Rehm J, Patra J, Zatonski W: Comparing alcohol consumption in central and eastern Europe to other European countries. Alcohol Alcohol 2007, 42:465-473.

12. Rehm J, Shield KD, Rehm MX, Gmel G Jr, Frick U: Alcohol Consumption, Alcohol Dependence, and Attributable Burden of Disease in Europe: Potential Gains From Effective Interventions For Alcohol Dependence. Centre for Addiction and Mental Health: Toronto, Canada; 2012.
13. Rehm J, Anderson P, Barry J, Dimitrov P, Elekes Z, Feijão F, Frick U, Gual A, Gmel GJ, Kraus L, Marmet S, Raninen J, Rehm MX, Scafato E, Shield KD, Trapencieris M, Gmel G: Prevalence and potential influencing factors of alcohol dependence in Europe. Eur Addict Res. in press.

14. Shield KD, Kehoe T, Gmel G, Rehm MX, Rehm J: Societal burden of alcohol. In Alcohol in the European Union Consumption, Harm And Policy Approaches. Edited by Anderson P, Møller L, Galea G. Copenhagen, Denmark: World Health Organization Regional Office for Europe; 2012:10-28.

15. Zatonski W, Manczuk M, Sulkowska U, HEM Project Team: Closing the Health Gap in European Union. Warsaw, Poland: Cancer Epidemiology and Prevention Division, the Maria Sklodowska-Curie Memorial Cancer Centre and Institute of Oncology; 2008. http://www.hem.waw.pl/.

16. The Organisation for Economic Co-operation and Development (OECD): Health at a Glance: Europe 2012. Paris, France: OECD Publishing; 2012. http://www.oecd.org/els/health-systems/HealthAtAGlanceEurope2012.pdf.

17. Shield KD, Parry C, Rehm J: Chronic diseases and conditions related to alcohol use. Alcohol Res 2013, 35:155-171.

18. Rehm J, Baliunas D, Borges GLG, Graham K, Irving HM, Kehoe T, Parry CD, Patra J, Popova L, Poznyak V, Roerecke M, Room R, Samokhvalov AV, Taylor $B$ : The relation between different dimensions of alcohol consumption and burden of disease - An overview. Addiction 2010, 105:817-843.

19. Chiang CL: Competing risks in mortality analysis. Annu Rev Public Health 1991, 12:281-307.

20. National Health Medical Research Council: Australian Drinking Water Guidelines. Canberra: National Health and Medical Research Council (NHMRC); 2004.

21. Hunter PR, Fewtrell L: Acceptable risk. In Water Quality: Guidelines, Standards and Health. Edited by Fewtrel L, Bartram J. London, UK: IWA Publishing; 2001:207-227.

22. Rifkin E, Bouwer E: The Illusion of Certainty: Health Benefits and Risks. New York: Springer; 2007.

23. The myth of $10^{-6}$ as a definition of acceptable risk. http://www.safedriver. gr/studies/KINDYNOS/THE\%20MYTH\%200F\%2010-6\%20AS\%20A\% 20DEFINITION\%20OF\%20ACCEPTABLE\%20RISK.pdf.

24. Coleman MP, Aylin P: Death Certification and Mortality Statistics: an International Perspectives (Studies on Medical and Population Subjects \# 64). The Stationary Office: London, UK; 2000.

25. Rehm J, Gmel G, Rehm MX, Scafato E, Shield KD: What can alcohol do to European societies? In Alcohol Policy in Europe: Evidence From AMPHORA. The AMPHORA project. 2nd edition. Edited by Anderson P, Braddick F, Reynolds J, Gual A. Barcelona, Spain: AMPHORA project; 2013:4-16. http://www.amphoraproject.net/.

26. World Health Organization - International Programme on Chemical Safety: Environmental Health Criteria 239 - Principles for Modelling Dose-response for the Risk Assessment of Chemicals. Geneva, Switzerland: World Health Organization; 2009.

27. Lachenmeier DW, Kanteres F, Rehm J: Epidemiology-based risk assessment using the benchmark dose/margin of exposure approach: the example of ethanol and liver cirrhosis. Int J Epidemio/ 2011, 40:210-218.

28. Laslett AM, Room R, Ferris J, Wilkinson C, Livingston M, Mugavin J: Surveying the range and magnitude of alcohol's harm to others in Australia. Addiction 2011, 106:1603-1611.

29. Hope A: Alcohol's Harm to Others in Ireland. Health Service Executive: Dublin, Ireland; 2014.

30. Laslett AM, Catalano P, Chikritzhs T, Dale C, Doran C, Ferris J, Jainullabudeen T, Livingston M, Matthews S, Mugavin S, Room R, Schlotterlein M, Wilkinson C: The Range and Magnitude of Alcohol's Harm to Others. Turning Point Alcohol \& Drug Centre: Fitzroy, AU; 2010.

31. Bruun K, Pan L, Rexed I: The Gentlemen's Club: International Control of Drugs and Alcohol. Chicago: University of Chicago Press; 1975.

32. Nutt DJ, King LA, Phillips LD, For the Independent Scientific Committee on Drugs: Drug harms in the UK: a multicriteria decision analysis. Lancet 2010, 376:1558-1565.

33. Schrad ML: The Political Power of Bad Ideas: Networks, Institutions, and the Global Prohibition Wave. New York: Oxford University Press; 2010.

34. Casswell S, Thamarangsi T: Reducing the harm from alcohol: call to action. Lancet 2009, 373:2247-2257.

35. World Health Organization: WHO Expert Committee on Drug Dependence Thirty fifth report. WHO Technical Report Series number 973. Geneva, Switzerland: World Health Organization; 2012. http://apps.who.int/iris/ bitstream/10665/77747/1/WHO_trs_973_eng.pdf. 
36. International Agency for Research on Cancer: Personal Habits and Indoor Combustions. Lyon, France: International Agency for Research on Cancer; 2012.

37. Lachenmeier DW, Przybylski MC, Rehm J: Comparative risk assessment of carcinogens in alcoholic beverages using the margin of exposure approach. Int J Cancer 2012, 131:E995-E1003.

38. Proposition 65 of the Office of Environmental Health Hazard Assessment of California. http://oehha.ca.gov/prop65/law/12601.html.

39. Room R: Alcohol control and public health. Annu Rev Public Health 1984, 5:293-317.

40. Alcohol use and cancer in Canada; Cancer Control Snapshot \# 5 . http://www.cancerview.ca/idc/groups/public/documents/webcontent/ rl_cr__snapshot_5.pdf.

41. American Institute for Cancer Research: The AICR 2013 Cancer Risk Awareness Survey. Washington, DC: American Institute for Cancer Research; 2013.

42. Sanderson SC, Waller J, Jarvis MJ, Humphries SE, Wardle J: Awareness of lifestyle risk factors for cancer and heart disease among adults in the UK. Patient Educ Couns 2009, 74:221-227.

43. European Commission: EU Citizens' Attitudes Towards Alcohol, Special Eurobarometer 331. TNS Opinion: Brussels, Belgium; 2010

44. Fischhoff B, Lichtenstein S, Slovic P, Derby SL, Keeney RL: Acceptable Risk. Cambridge, UK: Cambridge University Press; 1981.

45. Gigerenzer G: Risk Sarry: How to Make Good Decisions. New York: Penguin; 2013.

46. Bogg T, Roberts BW: Conscientiousness and health-related behaviors: a meta-analysis of the leading behavioral contributors to mortality. Psychol Bull 2004, 130:887-919.

47. Sjöberg L: Risk perception of alcohol consumption. Alcohol Clin Exp Res 1998, 22:277S-284S.

48. Klingemann H, Gmel G: Mapping Social Consequences of Alcohol Consumption Dordrecht, Netherlands: Kluwer Academic Publishers; 2001.

49. Babor T, Caetano R, Casswell S, Edwards G, Giesbrecht N, Graham K, Grube J, Gruenewald P, Hill L, Holder H, Homel R, Livingston M, Österberg E, Rehm J, Room R, Rossow I: Alcohol: No Ordinary Commodity. Research and Public Policy. 2nd edition. Oxford, UK: Oxford University Press; 2010.

50. Chisholm D, Rehm J, van Ommeren M, Monteiro M: Reducing the global burden of hazardous alcohol use: a comparative cost-effectiveness analysis. J Stud Alcohol 2004, 65:782-793.

51. Wilkinson C, Room R: Warnings on alcohol containers and advertisements: international experience and evidence on effects. Drug Alcohol Rev 2009, 28:426-435.

52. Nutt D: Drugs Without the Hot Air. Cambridge, UK: UIT Cambridge Ltd.; 2012.

53. Martinic M, Leigh B: Reasonable Risk: Alcohol in Perspective. New York: Brunner-Routledge; 2004.

54. World Health Organization: Global Strategy to Reduce the Harmful Use of Alcohol. Geneva, Switzerland: World Health Organization; 2010.

doi:10.1186/s12916-014-0189-z

Cite this article as: Rehm et al:: Why does society accept a higher risk for alcohol than for other voluntary or involuntary risks? BMC Medicine 2014 12:189.

\section{Submit your next manuscript to BioMed Central and take full advantage of:}

- Convenient online submission

- Thorough peer review

- No space constraints or color figure charges

- Immediate publication on acceptance

- Inclusion in PubMed, CAS, Scopus and Google Scholar

- Research which is freely available for redistribution 